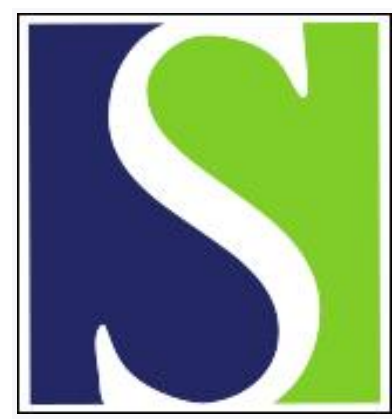

Scand J Work Environ Health 1992;18(4):225-232

https://doi.org/10.5271/sjweh.1585

Issue date: 01 Aug 1992

Occupational exposure to sulfuric acid in southern Ontario, Canada, in association with laryngeal cancer.

by Soskolne $\mathrm{CL}$, Jhangri GS, Siemiatycki J, Lakhani R, Dewar R, Burch $J D$, Howe GR, Miller AB

Affiliation: Department of Health Services Administration and Community Medicine, Faculty of Medicine, University of Alberta, Edmonton, Canada.

This article in PubMed: www.ncbi.nlm.nih.gov/pubmed/1411364 


\title{
Occupational exposure to sulfuric acid in southern Ontario, Canada, in association with laryngeal cancer
}

\author{
by Colin L Soskolne, PhD, ${ }^{1}$ Gian S Jhangri, MSc, ${ }^{1}$ Jack Siemiatycki, PhD, ${ }^{2}$ \\ Ramzan Lakhani, DipHyg, ${ }^{2}$ Ron Dewar, MSc, ${ }^{2} \mathrm{~J}$ David Burch, MA, ${ }^{3,4}$ \\ Geoffrey R Howe, $\mathrm{PhD}^{3,4}$ Anthony B Miller, $\mathrm{MB}^{4}$
}

\begin{abstract}
SOSKOLNE CL, JHANGRI GS, SIEMIATYCKI J, LAKHANI R, DEWAR R, BURCH JD, HOWE GR, MILLER AB. Occupational exposure to sulfuric acid in southern Ontario, Canada, in association with laryngeal cancer. Scand $J$ Work Environ Health 1992;18:225-32. A case-referent study, designed to test associations between asbestos, nickel, and the development of laryngeal cancer, was conducted in southern Ontario in 1977-1979. The cases were individually matched to neighborhood referents for gender and age. This constituted the primary study. Personal interviews had secured tobacco, alcohol, and detailed work histories. To 183 of the male pairs was added retrospective assessments of sulfuric acid exposure for each job, blind of disease status; this constituted the data base for an augmented secondary analysis. Logistic regression revealed statistically significant odds ratios when tobacco and alcohol were controlled. Exposure-response gradients were strongly positive with odds ratios in the range of 1.97 [ $95 \%$ confidence interval $(95 \%$ CI) $0.63-6.13$ ] for short duration-low level exposure through 6.91 [95\% CI 2.20-21.74] for long duration-higher level exposure employing progressively more specific definitions of exposure. Asbestos as a confounder and the interaction terms examined were nonsignificant. These findings are corroborative of those of other studies.
\end{abstract}

Key terms: alcohol, asbestos, case-referent study, job-exposure matrix, occupational histories, personal interviews, population-based, secondary data analysis, tobacco.

The question of inhaling acid mists in the workplace in relation to respiratory carcinogenesis was first noted in 1937 by Campbell (1). His review article included a hospital case series reported by Alwens et al (2) a year earlier. From this case series, Campbell noted the existence of four workers with bronchial cancer who had worked exclusively with hydrochloric and sulfuric acids. He speculated that the chemical fumes may be injurious to individuals susceptible to lung cancer. The question resurfaced from time to time through the 1950s with reports of respiratory tract cancer, including cancers of the lung and larynx, but, more specifically, cancers of the paranasal sinuses (3-5). The focus on laryngeal cancer, however, was identified most recently through an excess incidence associated with work on the ethanol unit of a petrochemical plant which used sulfuric acid in excess of $90 \%$ concentration in water ("strong" acid) (6). The inference was drawn that diethyl sulfate, present in the ethanol

\footnotetext{
1 Epidemiology Program, Department of Health Services Administration and Community Medicine, Faculty of Medicine, University of Alberta, Edmonton, Alberta, Canada.

2 Unité de recherche Epidemiologique, Institut ArmandFrappier, Université du Quebéc (Epidemiologic Research Unit, Armand-Frappier Institute, University of Quebec), Laval, Quebec, Canada.

3 Epidemiology Unit, National Cancer Institute of Canada.

4 Department of Preventive Medicine and Biostatistics, University of Toronto, Toronto, Ontario, Canada.
}

Reprint requests to: Dr CL Soskolne, Epidemiology Program, University of Alberta, 13-103 Clinical Sciences Building, Edmonton, Alberta, Canada T6G $2 \mathrm{G} 3$. process, could have been the active carcinogen. The dialkyl sulfates are known to be strong alkylating agents.

Since these reports, a series of studies has been reported which focused more specifically on sulfuric acid exposure in the workplace (7-13). Each of these studies demonstrated effects with relative risk estimates for respiratory tract cancers in the range of 2 to 13 . In only one study of laryngeal cancer (14) were statistically increased risks found, among others, for workers in metal fabricating [odds ratio (OR) 2.1], but reduced risks were reported for workers with potential exposure to sulfuric acid (OR 0.8 ).

The possible role of sulfuric acid as it relates to enhancing susceptibility to cancer has been previously reviewed (15). The evidence between sublethal exposures to acidic pollutants and chronic health effects were examined in relation to possible biological mechanisms. The analyses reported in this presentation were designed to evaluate the association between workplace exposure to sulfuric acid and the development of laryngeal cancer.

\section{Subjects and methods}

A case-referent, population-based interview study was conducted in southern Ontario among 204 incident cases of histologically confirmed laryngeal cancer diagnosed between 1977 and 1979 and 204 referents individually matched for gender, age ( \pm 5 years), and 
neighborhood of residence. The patients were residents of four cities, Toronto, Hamilton, Sudbury, and North Bay. The cases were ascertained through the only two cancer treatment centers in the study area, which are the Princess Margaret Hospital in southern Ontario and the Hamilton Cancer Clinic. Ear, nose and throat specialists referred the few remaining patients who did not seek radiotherapy treatment at one of the two cancer centers. All of the subjects were interviewed in their homes. This study focused primarily on tobacco, alcohol, asbestos, and nickel, and it has been fully described elsewhere (16). In summary, the odds ratio was 5.4 [95\% confidence interval $(95 \% \mathrm{CI}) 2.6-11.3]$ for the highest level of tobacco consumption, $4.8(95 \%$ CI 2.3-9.9) for the highest level of alcohol consumption, $5.1(\mathrm{P}=0.083)$ for definite asbestos exposure, and $0.4(\mathrm{P}=0.093)$ for definite nickel exposure. The latter three odds ratios were controlled for tobacco consumption. The present study, restricted to the men, was devised to evaluate occupational sulfuric acid exposure. A total of 183 pairs of cases and referents was included. One pair had to be dropped from the 184 initial male pairs after it was found that the case had been incorrectly diagnosed. The mean ages at the time of the interview of the 183 male cases and their 183 matched referents included in the primary study were 62.4 (SD 9.88, range 38.12-84.75) years and 63.1 (SD 9.94, range $39.51-87.26$ ) years, respectively. The cases were histologically confirmed cases of carcinoma of the larynx, newly diagnosed from March 1977 through July 1979. Table 1 shows the site-specific frequency distribution of the cases. The three most common sites were the glottis $(57.4 \%)$, unspecified site $(20.2 \%)$, and supraglottis $(14.2 \%)$.

From the interviewer-administered questionnaires of the primary study, each work experience was extracted (including period, occupation, job title, and employer) and, blind of case or referent status, sent to one of the authors (RL) for retrospective assessment of exposure to sulfuric acid for each job held by all of the study subjects. The approach used was one developed for a large case-referent study in Montreal in which this author had participated. These methods have been described elsewhere (18-22). Briefly, each job descrip-

Table 1. Distribution of 183 laryngeal cancer cases from southern Ontario in 1977-1979 by site category titles according to ICD9-CM. ${ }^{\mathrm{a}}$

\begin{tabular}{llrr}
\hline ICD & ICD & $\mathrm{N}$ & $\%$ \\
code & description & 105 & 57.38 \\
161.0 & Glottis & 26 & 14.21 \\
161.1 & Supraglottis & 1 & 0.55 \\
161.2 & Subglottis & 1 & 0.55 \\
161.3 & Laryngeal cartilages & 13 & 7.10 \\
161.8 & Other specified parts & 37 & 20.22 \\
161.9 & Larynx, unspecified & 183 & 100.00 \\
\hline Overall & & 18 \\
\hline
\end{tabular}

a International Classification of Diseases, 9th revision, clinical modification (17). tion was examined by RL individually and, on the basis of his knowledge of the occupation, industry, and era, he coded the job as exposed or unexposed to sulfuric acid. If the subject was considered to be exposed, this exposure was further characterized by one of three levels on each of three scales of concentration, frequen$c y$, and certainty. The sources of information used by $\mathrm{RL}$ in this exposure assessment were mainly bibliographic. Technical literature concerning sulfuric acid use and exposure in different industries was collected from a variety of sources. Much relevant information was collected in the large Montreal case-referent study on sulfuric acid exposure in different occupations, and this information was used judiciously. No measurements were carried out for this study; however, RL visited the area of study and had discussions with various local hygiene and engineering experts to help him assess the specificity of the local situation.

Exposure to sulfuric acid was rated on three ordinal four-point scales of concentration $(0=$ none/unexposed, 1 =low, 2 =medium, 3 =high), frequency $(0=$ none/unexposed, $1=$ low $[1-<5 \%$ of workday], $2=$ medium [5-30\% of workday], $3=$ high [ $>30 \%$ of workday]), and certainty associated with the concentration and frequency assessments $(0=$ not applicable/unexposed; 1 = possible, but not probable; $2=$ probable; $3=$ certain). These three scales are amenable to numerous arithmetic manipulations.

The concentration scale was not based on absolute quantitative cutpoints. Instead it was based on establishing certain occupational circumstances as typical of low, medium, and high exposure conditions and then using judgment to rate the jobs in the study against these benchmarks. To provide some relational idea about the quantitative meaning of the categories used in assessing concentration, low, medium, and high roughly corresponded to $<0.1,0.1-0.9$, and $\geq 1.0 \mathrm{mg} \cdot \mathrm{m}^{-3}$, respectively.

The simplest method used to distinguish the "exposed" from the "unexposed" was to consider concentration $\geq 1$, frequency $\geq 1$, and certainty $\geq 1$, in any job of any duration $\geq 1$ day as exposed; if each of the three scales were rated zero, then the person was considered unexposed. Duration was calculated directly on the basis of the stated period of employment in the particular job. It was calculated up to the date of diagnosis of the case and to the same date for the matched referent.

A more integrated assessment of exposure over an entire work history was calculated by summing the product of concentration, frequency, and certainty over each job, squaring the result, and multiplying by duration at that job to provide a "cumulative exposure index" (19). The latter was then divided by duration of exposure at any concentration or frequency $\geq 1$ to provide the "average exposure level" over a working lifetime or to the date of diagnosis of the case in each matched pair, whichever occurred earlier. This measure allowed the classification of each subject into one 
of three categories of exposure. There was "no exposure," and then the median of the frequency distribution for the average exposure level for both the cases and referents served to distinguish "high-level exposure" from "low-level exposure." The three categories of exposure then enabled modeling two $0 / 1$ dummy exposure variables. It was also possible to be stricter in the definition of exposure by requiring higher rankings on each or on both of the concentration and frequency scales. In the latter situation, the duration (in calculating the denominator for determining the average exposure level) included only those durations in jobs assessed as having concentrations or frequencies or both at the same ranking as used in the numerator for the calculation of the cumulative exposure index.

To incorporate duration of exposure into the exposure variable, an ordinal scale $(0 / 1 / 2 / 3 / 4)$ was developed with a cutoff at 10 years as follows: $0=$ no exposure; $1=$ short duration ( $\leq 10$ years)-low exposure; $2=$ long duration $(>10$ years)-low exposure; $3=$ short duration ( $\leq 10$ years)-high exposure; and $4=$ long duration ( $>10$ years)-high exposure. This technique allowed modeling four $0 / 1$ dummy variables.

To ensure both the appropriateness of the modeling strategies and to gain insight into the data, we analyzed the data set without regard of the matching and without control for known confounders; retaining the matching, but without control for confounders or interaction terms; and by logistic regression using conditional maximum likelihood estimation techniques. Initially, backwards elimination from as fully saturated a model as possible was the strategy employed, using full confounder and multiplicative interaction terms. The most parsimonious models were those subsequently used in a forward selection strategy. They are the models presented.

Confounders were obtained directly from the primary data set by methods described elsewhere (16). In summary, because asbestos was found to be a significant risk factor in the primary study, it was included in some of the models, but found not to be a significant confounder. Hence asbestos was not included in any of the models presented. Nickel was not found to be a significant factor in the primary study. Life-style variables of tobacco and alcohol consumption were obtained in the primary study as part of the home-based questionnaire administered by a trained interviewer. Following the approach used in the primary data analysis, tobacco and alcohol lifetime consumption were modeled as single, four-level categorized variables. Tobacco was categorized as $<150000,150000-$ 299000 , and $\geq 300000$ cigarettes over a lifetime; alcohol was categorized as $<10000,10000-26000$, $\geq 26000$ ounces of alcohol over a lifetime (1 ounce $=$ 0.02957 liters). In all of the models, the reference category for tobacco and alcohol was "never used."

Some of the published results (16) from the primary data set were first replicated to ensure consistency in the definition of the variables used in the secondary, augmented data analysis reported in this presentation.

Analyses were carried out with three different methods for classifying exposure status. First, all of the data analyses were based on the most sensitive definition of exposure to sulfuric acid, namely, that with any concentration, frequency, and certainty score of $\geq 1$. Under this most sensitive definition, table 2 shows the distribution of exposure among the cases and referents. Among the referents, $51.4 \%$ was exposed for at least $1 \mathrm{~d}$ in their work history by this definition; sulfuric acid is, after all, one of the most commonly manufactured chemicals sold in the United States (23).

Second, a slightly more specific, stricter definition was used which required that the certainty score be increased from $\geq 1$ to $\geq 2$, and exposures that may have occurred within the five-year period preceding the date of diagnosis (ie, within a lag period of five years) were ignored. Under the first and most sensitive definition, the lifetime prevalence of exposure among the cases and referents combined was $62.0 \%$, or, as noted earlier, among only the referents, it was $51.4 \%$. Under the second and stricter definition of exposure (table 2), the combined lifetime prevalence was $35.0 \%$, or among only the referents it was $25.1 \%$, identifying a category of questionably exposed subjects under this definition.

Third, a most specific definition of exposure was also used, those exposed being classified into two categories, substantial and probable exposure. Substantial exposure was defined as concentration, frequen$\mathrm{cy}$, and certainty $\geq 2$ and at least five years of accumulated duration not within a lag period of five years; all other exposures were classified as probable exposure. Then, the combined lifetime prevalence for those with substantial exposure was $10.1 \%$ or, among only the referents, $6.6 \%$ (table 3 ).

When the frequency distributions of tobacco and alcohol on an ordinal scale of "no," "low," "moderate," and "high" consumption were considered, all of the cells contained $\geq 30$ subjects, except for the number of nonsmoking cases, for whom the cell size was 12 , and that of the nonalcohol consuming cases was 27 , each representing a substantial deficit over expected. Therefore, at all consuming levels, more cases than referents tended to smoke tobacco and drink alcohol, especially at the highest levels.

Attempts to examine possible interaction in the models rendered nonsignificant effects when $\mathrm{P}<0.10$ was used to decide the significance for the inclusion of interaction terms. Interaction between tobacco and alcohol, sulfuric acid and tobacco, and sulfuric acid and alcohol was examined with the use of the slightly more specific, stricter definition of sulfuric acid exposure with a five-year lag period. The logistic regression coefficients for the interaction terms between tobacco and alcohol, sulfuric acid and tobacco, and sulfuric acid and alcohol were $-0.10(95 \% \mathrm{Cl}$ $-0.31-0.12),-0.15(95 \% \mathrm{CI}-0.75-0.44)$, and 
Table 2. Exposure distribution of all of the study subjects by case $(N=183)$ or referent $(N=183)$ status.

\begin{tabular}{|c|c|c|c|c|c|c|c|c|}
\hline \multirow{3}{*}{ Exposure classification } & \multicolumn{4}{|c|}{ Most sensitive exposure ${ }^{a}$} & \multicolumn{4}{|c|}{ More specific exposure ${ }^{b}$} \\
\hline & \multirow{2}{*}{$\begin{array}{l}\text { Cases } \\
(\mathrm{N})\end{array}$} & \multirow{2}{*}{$\begin{array}{l}\text { Referents } \\
\text { (N) }\end{array}$} & \multicolumn{2}{|c|}{ Total } & \multirow{2}{*}{$\begin{array}{l}\text { Cases } \\
(\mathbf{N})\end{array}$} & \multirow{2}{*}{$\begin{array}{l}\text { Referents } \\
\text { (N) }\end{array}$} & \multicolumn{2}{|c|}{ Total } \\
\hline & & & $\mathrm{N}$ & $\%$ & & & $\mathbf{N}$ & $\%$ \\
\hline Not exposed & 50 & 89 & 139 & 38.0 & 50 & 89 & 139 & 38.0 \\
\hline Questionable exposurec & $\cdot$ & $\cdot$ & $\cdot$ & $\cdot$ & 51 & 48 & 99 & 27.0 \\
\hline \multicolumn{9}{|l|}{ Short duration ( $\leq 10$ years) } \\
\hline $\begin{array}{l}\text { Low exposure } \\
\text { High exposure }\end{array}$ & $\begin{array}{l}10 \\
10\end{array}$ & $\begin{array}{l}16 \\
11\end{array}$ & $\begin{array}{l}26 \\
21\end{array}$ & $\begin{array}{l}7.1 \\
5.7\end{array}$ & $\begin{array}{l}12 \\
15\end{array}$ & $\begin{array}{c}9 \\
10\end{array}$ & $\begin{array}{l}21 \\
25\end{array}$ & $\begin{array}{l}5.7 \\
6.8\end{array}$ \\
\hline \multicolumn{9}{|l|}{ Long duration (>10 years) } \\
\hline $\begin{array}{l}\text { Low exposure } \\
\text { High exposure }^{d}\end{array}$ & $\begin{array}{l}50 \\
63\end{array}$ & $\begin{array}{l}38 \\
29\end{array}$ & $\begin{array}{l}88 \\
92\end{array}$ & $\begin{array}{l}24.0 \\
25.2\end{array}$ & $\begin{array}{l}29 \\
26\end{array}$ & $\begin{array}{l}14 \\
13\end{array}$ & $\begin{array}{l}43 \\
39\end{array}$ & $\begin{array}{l}11.8 \\
10.7\end{array}$ \\
\hline
\end{tabular}

a Exposure defined as concentration $\geq 1$; frequency $\geq 1$; certainty $\geq 1$; a lag period of 0 years is considered.

b Exposure defined as concentration $\geq 1$; frequency $\geq 1$; certainty $\geq 2$; a lag period of 5 years is considered.

c Only applicable to analyses using the definition of more specific exposure; if exposure was attributed at the lowest certainty level (ie, certainty =1) or if any exposure occurred within a lag period of five years (ie, within five years of the date of diagnosis), then the subject was considered as neither exposed nor unexposed and was classified as having questionable exposure.

d The median was used to separate low from high exposures.

Table 3. Exposure distribution of all of the study subjects by case $(N=183)$ or referent $(N=183)$ status.

\begin{tabular}{|c|c|c|c|c|}
\hline \multirow{3}{*}{ Exposure classification } & \multicolumn{4}{|c|}{ Most specific exposure ${ }^{a}$} \\
\hline & \multirow{2}{*}{ Cases } & \multirow{2}{*}{ Referents } & \multicolumn{2}{|c|}{ Total } \\
\hline & & & $\mathbf{N}$ & $\%$ \\
\hline Not exposed & 50 & 89 & 139 & 38.0 \\
\hline Questionable exposureb & 51 & 48 & 99 & 27.0 \\
\hline \multicolumn{5}{|l|}{ Short duration ( $\leq 10$ years) } \\
\hline $\begin{array}{l}\text { Probable exposurec } \\
\text { Substantial exposure }\end{array}$ & $\begin{array}{r}23 \\
6\end{array}$ & $\begin{array}{r}16 \\
4\end{array}$ & $\begin{array}{l}39 \\
10\end{array}$ & $\begin{array}{r}10.7 \\
2.7\end{array}$ \\
\hline \multicolumn{5}{|l|}{ Long duration ( $>10$ years) } \\
\hline $\begin{array}{l}\text { Probable exposurec } \\
\text { Substantial exposure }\end{array}$ & $\begin{array}{l}34 \\
19\end{array}$ & $\begin{array}{r}18 \\
8\end{array}$ & $\begin{array}{l}52 \\
27\end{array}$ & $\begin{array}{r}14.2 \\
7.4 \\
\end{array}$ \\
\hline \multicolumn{5}{|c|}{$\begin{array}{l}\text { Exposure defined as concentration } \geq 1 \text {; frequency } \geq 1 \text {; certainty } \geq 2 \text {; } \\
\text { a lag period of five years is considered. } \\
\text { b If exposure was attributed at the lowest certainty level (ie, certainty }=1 \text { ) } \\
\text { or if any exposure occurred within a lag period of five years (ie, within } \\
\text { five years of the date of diagnosis), then the subject was considered } \\
\text { as neither exposed nor unexposed and was classified as having ques. } \\
\text { tionable exposure. } \\
\text { c Exposure has been classified into two mutually exclusive categories: } \\
\text { those with greater (ie, substantial) exposure and those with lesser (ie, } \\
\text { probabie) exposure. Substantial exposure is defined as concentration } \\
\geq 2 \text { and frequency } \geq 2 \text { and certainty } \geq 2 \text { and at least five years of ac- } \\
\text { cumulated duration not within a lag period of five years (ie, not within } \\
\text { five years of the date of diagnosis). All of the other exposures have } \\
\text { been classified as probable exposure. }\end{array}$} \\
\hline
\end{tabular}

$-0.08(95 \%$ CI $-0.61-0.43)$, respectively. In this modeling, exposure to sulfuric acid was classified into three categories, tobacco and alcohol were classified as single four-level variables, and a single product interaction term was included. None of the interaction coefficients were statistically significant. If the tobacco or alcohol interaction term had been statistically significant, it would have meant that the sulfuric acidlaryngeal cancer odds ratios could not have been considered uniform across increasing levels of either tobacco or alcohol consumption.

Attempts were made to explore possible interactions further by examining the effect of sulfuric acid exposure on smokers and nonsmokers, drinkers and non- drinkers, and among individuals exposed or not exposed to asbestos. When drinkers and nondrinkers were examined with sulfuric acid exposure classified into three categories and with tobacco as a single fourlevel variable, the acid-disease odds ratios were 3.53 $(95 \%$ CI $1.80-6.93)$ for the drinkers and $3.83(95 \%$ CI $0.63-23.31$ ) for the nondrinkers. The number of matched pairs in the nondrinker subgroup was merely 27 , a value rendering any interpretation of interaction difficult. Unfortunately, because of the small sample sizes in the nonsmoker subgroup $(\mathrm{N}=12)$ and in the subgroup with asbestos exposure $(\mathrm{N}=14)$, analyses were not possible (the coefficients would not converge).

\section{Results}

The odds ratios generally remained statistically significantly elevated and stable when sulfuric acid exposure was treated according to stricter definitions, or when the five-year period prior to diagnosis was discounted (ie, when a lag period of five years was considered). A variety of results is presented across the various exposure definitions.

For completeness, selected crude, unmatched odds ratios are presented from only the second definition, more specific exposure (table 2). The six-category classification yielded the following odds ratios: questionable exposure 1.89 (95\% CI 1.12-3.19); short duration-low exposure 2.37 (95\% CI 0.95-5.93); short duration-high exposure 2.67 (95\% CI 1.14-6.27); long duration-low exposure 3.69 (95\% CI 1.82-7.46); and long duration-high exposure 3.56 (95\% CI 1.72-7.38). The sulfuric acid-laryngeal cancer matched odds ratios, with no control for confounders, were $2.06(95 \%$ CI 1.16-3.64) for the questionable exposure category, 2.19 (95\% Cl 0.82-5.80) for short duration-low exposure, 2.96 (95\% CI 1.19-7.36) for short durationhigh exposure, $4.13(95 \%$ CI $1.86-9.18)$ for long 
Table 4. Odds ratios ${ }^{a}$ for sulfuric acid exposure and laryngeal cancer according to two of three major definitions of exposure. ( $95 \% \mathrm{Cl}=95 \%$ confidence interval)

\begin{tabular}{|c|c|c|c|c|}
\hline \multirow{2}{*}{ Exposure classification } & \multicolumn{2}{|c|}{ Most sensitive exposure ${ }^{b}$} & \multicolumn{2}{|c|}{ More specific exposurec } \\
\hline & OR & $95 \% \mathrm{Cl}$ & OR & $95 \% \mathrm{Cl}$ \\
\hline \multicolumn{5}{|l|}{ Model A } \\
\hline $\begin{array}{l}\text { Questionable exposured } \\
\text { Exposed }\end{array}$ & $2.90^{* * *}$ & $1.62-5.20$ & $\begin{array}{l}2.05^{\star} \\
3.74^{\star \star \star}\end{array}$ & $\begin{array}{l}1.03-4.08 \\
1.94-7.22\end{array}$ \\
\hline \multicolumn{5}{|l|}{ Model B } \\
\hline $\begin{array}{l}\text { Questionable exposured } \\
\text { Low exposuree }^{\text {e }} \\
\text { High exposure }\end{array}$ & $\begin{array}{l}1.91 \\
4.28^{\star * *}\end{array}$ & $\begin{array}{c}0.97-3.78 \\
2.13-8.58\end{array}$ & $\begin{array}{l}2.06^{\star} \\
3.24^{* *} \\
4.45^{* * *}\end{array}$ & $\begin{array}{l}1.03-4.12 \\
1.49-7.07 \\
1.90-10.45\end{array}$ \\
\hline \multicolumn{5}{|l|}{ Model C } \\
\hline $\begin{array}{l}\text { Questionable exposured } \\
\text { Short duration ( } \leq 10 \text { years) }\end{array}$ & $\cdot$ & $\cdot$ & $2.06^{\star}$ & $1.02-4.18$ \\
\hline $\begin{array}{l}\text { Low exposure } \\
\text { High exposure }\end{array}$ & $\begin{array}{l}1.04 \\
1.62\end{array}$ & $\begin{array}{l}0.34-3.21 \\
0.47-5.67\end{array}$ & $\begin{array}{l}1.97 \\
3.57^{\star}\end{array}$ & $\begin{array}{l}0.63-6.13 \\
1.19-10.73\end{array}$ \\
\hline \multicolumn{5}{|l|}{ Long duration (>10 years) } \\
\hline $\begin{array}{l}\text { Low exposure } \\
\text { High exposure }\end{array}$ & $\begin{array}{l}2.23^{*} \\
5.24^{* * *} \\
\end{array}$ & $\begin{array}{l}1.07-4.64 \\
2.48-11.10 \\
\end{array}$ & $\begin{array}{l}4.30^{\star \star} \\
5.57^{\star *}\end{array}$ & $\begin{array}{r}1.69-10.91 \\
2.00-15.50 \\
\end{array}$ \\
\hline \multicolumn{5}{|c|}{$\begin{array}{l}\text { Odds ratios }(\mathrm{OR}) \text { based on the logistic regression model of cigarette lifetime consumption ( } 1 \text { categorized variable) }+ \text { alcohol } \\
\text { lifetime ounces of ethanol consumption ( } 1 \text { categorized variable). } \\
\text { Exposed is defined as concentration } \geq 1 \text {; frequency } \geq 1 \text {; certainty } \geq 1 \text {; a lag period of zero years is considered. } \\
\text { Exposed is defined as concentration } \geq 1 \text {; frequency } \geq 1 \text {; certainty } \geq 2 \text {; a lag period of five years is considered. } \\
\text { Only applicable to analyses using the definition of more specific exposure; if exposure was attributed at the lowest certainty } \\
\text { level (ie, certainty }=1 \text { ) or if any exposure occurred within a lag period of five years (ie, within five years of the date of diag- } \\
\text { nosis), then the subject was considered as neither exposed nor unexposed and was classified as having questionable ex- } \\
\text { posure; the remaining subjects were classified as exposed. } \\
\text { The median was used to separate low exposures from high exposures. } \\
P^{\prime}<0.05,{ }^{* *} P<0.01,{ }^{* *} P<0.001 \text {; otherwise, not statistically significant. }\end{array}$} \\
\hline
\end{tabular}

duration-low exposure, and $4.06(95 \%$ CI 1.77-9.33) for long duration-high exposure.

Table 4 shows the results for the most sensitive definition of exposure with a zero-year lag period and with the slightly more specific, stricter definition of exposure with a five-year lag period. These findings showed significant associations, as well as clear exposure-response relationships, both with duration excluded or included in the exposure variable. In all of the comparisons between the results with a zero- and five-year lag period, the latter tended to produce odds ratios approximately $5 \%$ higher.

In order to examine effects employing the third and most specific definition of exposure, we treated the exposure variable differently. Table 5 shows the results obtained with the most specific definition of exposure. They demonstrate even stronger exposure-response relationships, regardless of the method used for classifying exposure.

Most of the cases were of the "glottis" $(57.4 \%)$, with only one case in each of the "subglottis" and "laryngeal cartilages" sites. It was beyond the scope of the present study to investigate whether or not site-specific associations were discernable. However, two sites were examined in the present investigation: "glottis" with 105 case-referent pairs and supraglottis with just 26 case-referent pairs.

When only "glottis" cases and their matched referents were included in a model, with exposure defined according to the second, more specific definition, the odds ratios remained significantly elevated, but no exposure-response gradient was clearly demonstrated. Although the loss of statistical significance was only marginal (at the $5 \%$ level) in the model including duration, again no clear exposure-response gradient was discernible from the point estimates. When supraglottis was examined with exposure classified in three categories, and with tobacco and alcohol as single fourlevel variables, the acid-disease odds ratio remained elevated, but not statistically significantly so. The small sample size in this subgroup made any analysis, and hence any interpretation, hazardous.

\section{Discussion}

An association between exposure to sulfuric acid in the workplace, particularly at higher concentrations and over longer periods, and the development of laryngeal cancer was demonstrated with both tobacco and alcohol consumption controlled. Exposure-response relationships, in terms of both the amount of acid mists inhaled and the length of time over which such inhalation persisted, added evidence to implicate sulfuric acid in the causation of laryngeal cancer.

In this analysis, the role of asbestos, and any interaction between tobacco, alcohol, or both and sulfuric acid, were insignificant relative to the main effects of tobacco, alcohol and sulfuric acid. It was not within the scope of the present study to account for poten- 
Table 5. Odds ratios ${ }^{a}$ for sulfuric acid exposure and laryngeal cancer according to the most specific definition of exposure. ( $95 \% \mathrm{Cl}=95 \%$ confidence interval)

\begin{tabular}{|c|c|c|}
\hline \multirow{2}{*}{ Exposure classification } & \multicolumn{2}{|c|}{ Most specific exposure ${ }^{b}$} \\
\hline & OR & $95 \% \mathrm{Cl}$ \\
\hline \multicolumn{3}{|l|}{ Model $A$} \\
\hline $\begin{array}{l}\text { Questionable exposurec } \\
\text { Exposed }\end{array}$ & $\begin{array}{l}2.05^{\star} \\
3.74^{* * *}\end{array}$ & $\begin{array}{l}1.03-4.08 \\
1.94-7.22\end{array}$ \\
\hline \multicolumn{3}{|l|}{ Model $B$} \\
\hline $\begin{array}{l}\text { Questionable exposurec } \\
\text { Probable exposure } \\
\text { Substantial exposured }\end{array}$ & $\begin{array}{l}1.86 \\
2.95^{\star *} \\
4.32^{\star *}\end{array}$ & $\begin{array}{l}0.94-3.66 \\
1.50-5.83 \\
1.64-11.37\end{array}$ \\
\hline \multicolumn{3}{|l|}{ Model C } \\
\hline $\begin{array}{l}\text { exposure } \\
n(\leq 10 \text { years) }\end{array}$ & 1.96 & $0.97-3.92$ \\
\hline $\begin{array}{l}\text { Probable exposure } \\
\text { Substantial exposure }^{d}\end{array}$ & & $\begin{array}{l}1.09-6.49 \\
0.60-18.53\end{array}$ \\
\hline \multicolumn{3}{|l|}{ Long duration ( $>10$ years) } \\
\hline $\begin{array}{l}\text { Probable exposured } \\
\text { Substantial exposure }^{d}\end{array}$ & $\begin{array}{l}3.85^{\star \star} \\
6.91^{\star \star \star} \\
\end{array}$ & $\begin{array}{l}1.60-9.24 \\
2.20-21.74 \\
\end{array}$ \\
\hline \multicolumn{3}{|c|}{$\begin{array}{l}\text { Odds ratios (OR) based on the logistic regression model of } \\
\text { cigarette lifetime consumption (1 categorized variable) +al- } \\
\text { cohol lifetime ounces of ethanol consumption ( } 1 \text { categorized } \\
\text { variable). } \\
\text { bxposed is defined as concentration } \geq 1 \text {; frequency } \geq 1 \text {; cer- } \\
\text { tainty } \geq 2 \text {; a lag period of five years is considered. } \\
\text { c If exposure was attributed at the lowest certainty level (ie, } \\
\text { certainty }=1 \text { ) or if any exposure occurred within a lag period } \\
\text { of five years (ie, within five years of the date of diagnosis), } \\
\text { then the subject was considered as neither exposed nor un- } \\
\text { exposed and was classified as having questionable ex- } \\
\text { posure; the remaining subjects were classified as exposed. } \\
\text { d Exposure has been classified into two mutually exclusive } \\
\text { categories: those with greater (ie, substantial) exposure and } \\
\text { those with lesser (le, probable) exposure. Substantial ex- } \\
\text { posure is defined as concentration } \geq 2 \text { and frequency } \geq 2 \\
\text { and certainty } \geq 2 \text { and at least five years of accumulated } \\
\text { duration not within a lag period of five years (ie, not within } \\
\text { five years of the date of diagnosis). All of the other exposures } \\
\text { have been classified as probable exposure. } \\
\text { * } P<.05,{ }^{*} P<0.01, \star \star \star \\
\text { ly significant. }\end{array}$} \\
\hline
\end{tabular}

tial industrial exposures other than asbestos and nickel, evaluated in the primary study. The inclusion of asbestos in the models had virtually no effect on the odds ratio estimates for sulfuric acid. Therefore, the choice was made to present only the models excluding asbestos.

To date, two case-referent studies $(8-10)$ and three cohort studies $(7,12,13)$ have associated occupational acid exposure with the development of laryngeal cancer. One cohort study, designed to evaluate specifically the association between sulfuric acid exposure in the workplace and lung cancer (11), also rendered positive results. Brown et al (14) failed to find an association. However, their study dichotomized exposure into "ever versus never exposed" and thereby reduced its ability to detect "high-level exposure" effects because of a potential exposure dilution bias. This procedure could account for the inability of that study to demonstrate any laryngeal cancer effect with sulfuric acid exposure in the workplace.

With an exposure assessment procedure similar to that used in this study, it was found that the lifetime prevalence of exposure to sulfuric acid in Montreal was approximately $9 \%$ (22). Subjects were regarded as being exposed if the level of certainty was $\geq 2$ with a lag period of five years. This level is in contrast with the much higher one found in the present study. The difference is because of the heavy industry base in the southern Ontario study area. The prevalence of exposure is influenced by the historic existence of numerous sulfuric acid manufacturing and acid-using industries. Major industries that use sulfuric acid include iron and steel pickling; fertilizer production; soap production; storage-battery production; production of explosives, chemicals, and textile fibers; and petroleum refining. Some of the more heavily exposed occupations include metal drawing, metal extruding, and electroplating.

The mechanisms by which sulfuric acid may cause cancer have been considered elsewhere (15). They include a promotional or cocarcinogenic role, perhaps through direct chronic irritation induced through exposure; a genotoxic effect, owing to extra- and intracellular $\mathrm{pH}$ modulation, is also possible.

Despite the consistency of these findings with those from other studies (7-13), the possibility of concomitant workplace exposure(s) resulting in potential confounding cannot be completely ruled out. Exposures which have not been simultaneously controlled in this study (or in the other studies) include, for example, exposure to heat, dialkyl sulfates, noisy occupations, arsenic compounds, beryllium, chrome, and wood dust.

Because cumulative exposure (dose) may provide a more sensitive measure of effect, we analyzed the data accordingly. The odds ratios, however, were found not to differ significantly between the two approaches for summarizing worklife exposure. For example, when the more specific definition of exposure with a lag period of five years was used, cumulative exposure gave odds ratios of 3.17 (95\% CI 1.49-6.74) for low exposure and 4.59 (95\% CI 2.02-10.41) for high exposure, compared respectively with 3.24 (95\% CI $1.49-7.07)$ and $4.45(95 \%$ CI $1.90-10.45)$ when the average exposure level was used (table 4). Hence, regardless of the exposure measures used, consistent and almost identical results were obtained. A fuller discussion on the choice of worklife summary exposure measures has been provided elsewhere (24).

The methodology for assigning the degree of historical exposure to sulfuric acid in this study differed from that used in the case-referent within a cohort study conducted in Baton Rouge, Louisiana $(8,9)$. In the Baton Rouge study, a single six-point ordinal scale $(0-5)$ was applied, resulting in a narrower range of values than the range of values obtained in the southern Ontario data set through the manipulation of three four-point scales. Misclassification in the Baton Rouge data set has been shown to cause significant swings in the odds ratios derived from various summary work- 
life exposure measures. However, the average exposure-level summary measure was less sensitive to the effects of misclassification than were the other summary measures. This finding has been described elsewhere (24).

It would not be meaningful to relate the average exposure level derived by the methods used in this study to exposures in the occupational setting. The exposure measure used is a synthetic composite of concentration, frequency, and certainty, and it cannot be expressed on an interval scale. In providing an ordinal separation between lower and higher exposed workers, the exposure measure has internal coherence, but it has no external meaning.

In order to examine more precisely the role that duration of exposure to sulfuric acid plays in the pathogenesis of laryngeal cancer, a second paper based on this data set will provide a latency-induction analysis.

The utility and cost-effectiveness of augmenting a case-referent data set gathered for one purpose for testing further hypotheses is demonstrated through this study. It is estimated that this approach resulted in a cost-saving of about $80 \%$; CAD 50000 was the cost for the secondary study in contrast to an estimated five times greater amount (ie, CAD 250 000) for a full study.

The International Agency for Research on Cancer (IARC) recently determined that occupational exposure to strong-inorganic-acid mists containing sulfuric acid is a carcinogenic risk to humans (25). This finding is of concern because sulfuric acid has been very commonly used in industry. It remains to be determined if organs other than the larynx are at risk and if other acids are similarly carcinogenic. Finally, the mechanisms by which sulfuric and other acids may act in the causation of cancer need to be understood. Animal experiments could be helpful in this regard and are lacking in relation to sulfuric acid exposure.

\section{Acknowledgments}

This study was made possible by grant number $6609-$ 1442-58 from the National Health Research and Development Program (NHRDP) of Health and Welfare Canada. The abstracting from questionnaires of the detailed work histories was done by Ms N Ryan. Assistance in developing the NHRDP grant application was provided by Ms N Fraser-Lee.

This manuscript is based on an oral presentation made at the 22nd Annual Meeting of the Society for Epidemiologic Research, 14-16 June 1989, Birmingham, Alabama, United States, entitled "Laryngeal Cancer and Occupational Exposure to Sulfuric Acid: A Population-based, Case-control, Augmented Secondary Data Analysis."

The authors are grateful to Dr K Steenland for his review of the manuscript and, in particular, his input concerning interaction. The technical assistance of Ms $\mathrm{T}$ Whaley is gratefully acknowledged.

\section{References}

1. Campbell JA. Cancer of the human lung and animal experiment. J Ind Hyg Toxicol 1937;19:449-62.

2. Alwens W, Bauke EE, Jonas W. Aubfallende haufurg von bronchialkrebs bei arbeitern deschemischen industrie. Arch Gewerbepath Gewerbehyg 1936;7,69-84.

3. Weil CS, Smyth HF, Nale TW. Quest for a suspected industrial carcinogen. AMA Arch Ind Hyg 1952;5:53547.

4. Eckardt RE. Industrial carcinogenesis. In: Lanza AJ, Orr RH, ed. Modern monographs in industrial medicine. New York, NY: Grune \& Stratton, 1959:101-2.

5. Eckardt RE. Annals of industry - non-casualties of the work place. J Occup Med 1974;16:472-7.

6. Lynch J, Hanis NM, Bird MG, Murray KJ, Walsh JP. An association of upper respiratory cancer with exposure to diethyl sulfate. J Occup Med 1979;21:333-41.

7. Ahlborg G Jr, Hogstedt C, Sundell L, Äman C-G. Laryngeal cancer and pickling house vapors [letter]. Scand J Work Environ Health 1981;7:239-40.

8. Soskolne CL. Upper respiratory cancer among refinery and chemical plant workers: a case-control study in Baton Rouge, Louisiana. Diss Abst Int 1982;43(03): $327 \mathrm{p}$.

9. Soskolne CL, Zeighami EA, Hanis NM, Kupper LL, Herrmann N, Amsel J, et al. Laryngeal cancer and occupational exposure to sulfuric acid. Am J Epidemiol 1984;120:358-69.

10. Cookfair D, Wende K, Michalek A, Vena J. A casecontrol study of laryngeal cancer among workers exposed to sulfuric acid [abstract]. Am J Epidemiol 1985;122:521.

11. Beaumont JJ, Leveton J, Knox K, Bloom T, McQuiston $\mathrm{T}$, Young M, et al. Lung cancer mortality in workers exposed to sulfuric acid mist and other acid mists. J Natl Cancer Inst 1987;79:911-21.

12. Forastiere F, Valesini S, Salimei E, Magliola ME, Perucci CA. Respiratory cancer among soap production workers. Scand J Work Environ Health 1987;13:258-60.

13. Steenland K, Schnorr T, Beaumont J, Halperin W, Bloom $T$. Incidence of laryngeal cancer and exposure to acid mists. Br J Ind Med 1988;45:766-76.

14. Brown LM, Mason TJ, Pickle LW, Stewart PA, Buffler PA, Burau K, et al. Occupational risk factors for laryngeal cancer on the Texas gulf coast. Cancer Res 1988;48:1960-4.

15. Soskolne CL, Pagano G, Cipollaro M, Beaumont JJ, Giordano GG. Epidemiologic and toxicologic evidence for chronic health effects and the underlying biological mechanisms involved in sub-lethal exposures to acidic pollutants. Arch Environ Health 1989;44:180-91.

16. Burch JD, Howe GR, Miller AB, Semenciw R. Tobacco, alcohol, asbestos, and nickel in the etiology of cancer of the larynx. J Natl Cancer Inst 1981;67:1219-224.

17. International classification of diseases. 9th revision, clinical modification. Ann Arbor, MI: Edward Brothers Inc, 1980:97-8.

18. Siemiatycki J, Wacholder S, Richardson L, Dewar, R, Gérin M. Discovering carcinogens in the occupational environment: methods of data collection and analysis of a large case-referent monitoring system. Scand J Work Environ Health 1987;13:486-92.

19. Siemiatycki J, Richardson L, Gérin M, Goldberg M, Dewar R, Désy M, et al. Associations between several sites of cancer and nine organic dusts: results from an hypothesis-generating case-control study in Montreal, 1979-1983. Am J Epidemiol 1986;123:235-49.

20. Gérin M, Siemiatycki J, Kemper H, Bégin D. Obtaining occupational exposure histories in epidemiologic casecontrol studies. J Occup Med 1985;27:420-6.

21. Siemiatycki J, Dewar R, Nadon L, Gérin M, Richardson L, Wacholder S. Associations between several sites of cancer and twelve petroleum-derived liquids: results from a case-referent study in Montreal. Scand J Work 
Environ Health 1987;13:493-504.

22. Siemiatycki J, Gérin M, Dewar $R$, Nadon L, Lakhani $R$, Bégin D, et al. Risk factors for cancer in the workplace. Boca Raton, FL: CRC Press, 1991.

23. National Institute for Occupational Safety and Health. Criteria for a recommended standard: occupational exposure to sulfuric acid. Cincinnati, $\mathrm{OH}$ : Department of Health, Education and Welfare, 1974. (HEW publication; no (NIOSH) 74-128).

24. Suarez-Almazor ME, Soskolne CL, Fung K, Jhangri GS. Empirical assessment of the effect of different summary worklife exposure measures on the estimation of risk in case-referent studies of occupational cancer. Scand $\mathbf{J}$ Work Environ Health 1992;18:233-41.

25. International Agency for Research on Cancer (IARC). Strong acid mists and some other industrial exposures. Lyon: IARC. In press. (IARC monographs on the evaluation of carcinogenic risks to humans; vol 54.)

Received for publication: 2 October 1991 